\title{
Testosterone replacement in 49,XXXXY syndrome: andrological, metabolic and neurological aspects
}

\author{
Rossella Mazzilli', Michele Delfino', Jlenia Elia', Francesco Benedetti', Laura Alesi', \\ Luciana Chessa ${ }^{2}$ and Fernando Mazzilli'
}

${ }^{1}$ Andrology Unit ${ }^{2}$ Genetics Unit, Department of Clinical and Molecular Medicine, Sant'Andrea Hospital, University of Rome "Sapienza", Via di Grottarossa 1035, 00189 Rome, Italy

\author{
Correspondence \\ should be addressed \\ to R Mazzilli \\ Email \\ rossella.mazzilli@gmail.com
}

\section{Summary}

We report the case of a 19-year-old boy, presenting several congenital malformations (facial dysmorphisms, cardiac and musculoskeletal abnormalities), mental retardation, recurrent respiratory infections during growth and delayed puberty. Although previously hospitalised in other medical centres, only psychological support had been recommended for this patient. In our department, genetic, biochemical/hormonal and ultrasound examinations were undertaken. The karyotype was $49, X X X X Y$, a rare aneuploidy with an incidence of 1/85 000-100 000, characterised by the presence of three extra X chromosomes in phenotypically male subjects. The hormonal/biochemical profile showed hypergonadotropic hypogonadism, insulin resistance and vitamin D deficiency. The patient was then treated with testosterone replacement therapy. After 12 months of treatment, we observed the normalisation of testosterone levels. There was also an increase in pubic hair growth, testicular volume and penis size, weight loss, homeostatic model assessment index reduction and the normalisation of vitamin D values. Moreover, the patient showed greater interaction with the social environment and context.

\section{Learning points:}

- In cases of plurimalformative syndrome, cognitive impairment, recurrent infections during growth and, primarily, delayed puberty, it is necessary to ascertain as soon as possible whether the patient is suffering from hypogonadism or metabolic disorders due to genetic causes. In our case, the diagnosis of hypogonadism, and then of 49,XXXXY syndrome, was unfortunately made only at the age of 19 years.

- The testosterone replacement treatment, even though delayed, induced positive effects on: i) development of the reproductive system, ii) regulation of the metabolic profile and iii) interaction with the social environment and context.

- However, earlier and timely hormonal replacement treatment could probably have improved the quality of life of this subject and his family.

\section{Background}

49, XXXXY syndrome, first described by Fraccaro in 1960 (1), is a rare aneuploidy with an incidence of $1 / 85000$ 100000 (1) (2). It is characterised by the presence of three extra $\mathrm{X}$ chromosomes in subjects who are phenotypically male. This aneuploidy probably originates from non-disjunction of the $\mathrm{X}$ chromosome during both meiosis I and II. To date, few cases have been described (1) (2) (3) (4) (5) (6) (7) (8) (9); in such cases, the median age at the time of diagnosis was 4 months (2) (3). Some particular ultrasound findings (polyhydramnios or cystic hygroma) could be suggestive of this syndrome during pregnancy (4). 


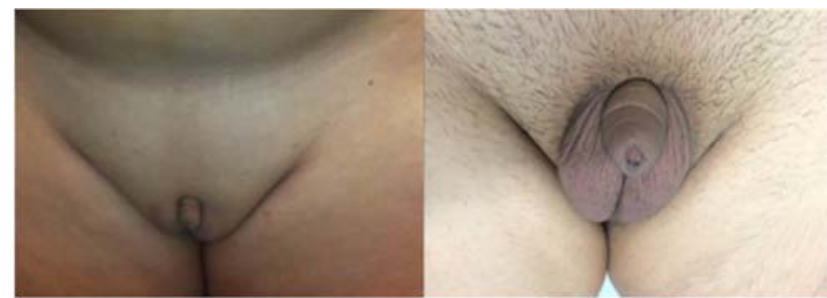

Figure 1

Scrotum and penis before (a) and after (b) testosterone replacement.

The clinical phenotype is characterised by complex plurimalformative syndrome: musculoskeletal anomalies (congenital talipes equinovarus, hypotonia, clinodactyly, radioulnar synostosis, scoliosis, hip dysplasia, pes cavus or planus) (3); alteration of neurocognitive development, mental retardation and brain malformations, such as white matter lesions (5); metabolic and hormonal alterations, such as hypergonadotropic hypogonadism, hypothyroidism and diabetes mellitus (6) (7) (8); and increased susceptibility to infections, atopy and immunodeficiency (9).

The 49,XXXXY syndrome differs from the Klinefelter syndrome with regards to intelligence quotient (IQ) scores (mean values in patients with 49, XXXXY $=20-60$ vs 89-102 in patients with $47, \mathrm{XXY}$ ) and to the different prevalence of congenital malformations (in 49,XXXXY = 50-100\%; in 47, XXY =18\%) (2). In fact, each additional $X$ chromosome confers a higher risk of congenital malformations (5).

\section{Case presentation}

Age at first examination was 19 years. Informed consent was given by the patient's parents.

Patient's history: No specific long-term therapy had been administered to the patient during his life.

There was no history of cardiovascular disease, diabetes mellitus, endocrinological pathologies or tumours. His parents were Caucasian and unrelated; maternal age at conception was 26 years. Vaginal delivery was at 38 weeks of gestation. Birth weight: $2.850 \mathrm{~kg}$; APGAR score 7 , breastfeeding and acquisition of the upright position at the age of 1 year.

Several congenital malformations (facial dysmorphisms, cardiac and musculoskeletal abnormalities) and mental retardation (IQ 34) were evident.

The patient suffered recurrent bacterial respiratory infections during his growth; these required only antibiotic treatment. At the age of 16, he was first hospitalised (not our hospital) for a more serious respiratory bacterial infection (severely elevated C-reactive protein, leukocytosis and high fever). He was successfully treated with antibiotics and paracetamol, which normalised all infection parameters. In particular, his clinical hospital record reported no signs or symptoms relating to the genital tract. During the hospitalisation, an MRI of the brain was also performed (most probably in connection with the mental retardation), which showed 'white matter lesions'. Mental retardation was confirmed, and only psychological support was recommended. No hormonal or genetic investigations were performed.

When he was 19 years old, his parents requested an andrological evaluation for delayed puberty. The parents reported that no investigation or treatment for this had ever been performed previously.

\section{Investigation}

\section{Physical examination}

Male phenotype, class II obesity (height $176 \mathrm{~cm}$; weight $112 \mathrm{~kg}$; BMI $36.2 \mathrm{~kg} / \mathrm{m}^{2}$ ), amimic face with hypertelorism and divergent strabismus and musculoskeletal anomalies: marked cervicodorsal kyphosis, both bilateral planus feet and hallux valgus.

\section{Andrological physical examination}

Hypo-representation of the pubic hair system, testicular hypoplasia (volume $2 \mathrm{ml}$ bilaterally, evaluated with a Prader orchidometer), non-palpable epididymis, micropenis $(2.1 \mathrm{~cm}$ length stretched) (Fig. 1a), Tanner stage I; autonomous walking with clumsiness and postural changes

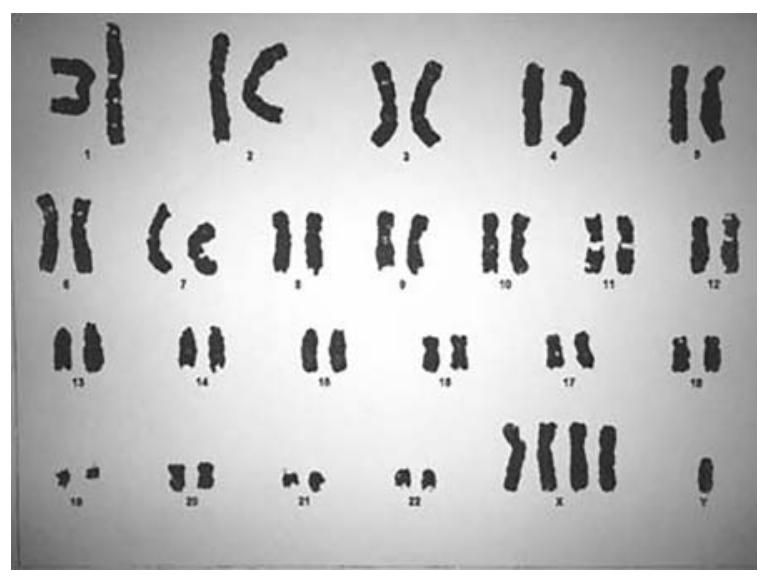

Figure 2

49,XXXXY karyotype (GTG banding). 


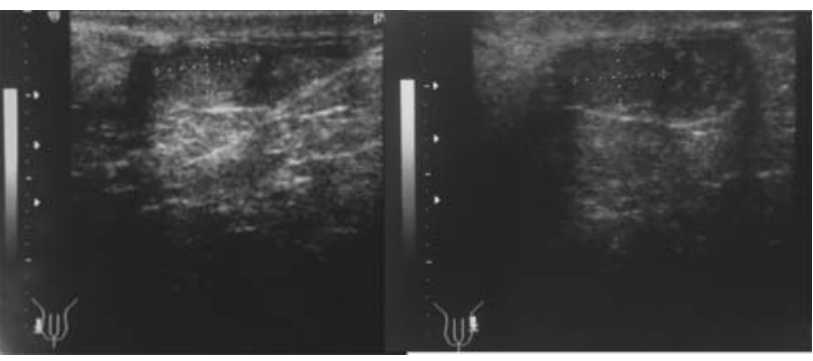

Figure 3

Testicular biometry.

if assisted; marked slowdown of ideomotor, fatuous attitude, lack of interaction with the social environment and context, speech delays and learning disabilities.

\section{Genetic study}

The karyotype was analysed on peripheral blood lymphocytes cultured for $72 \mathrm{~h}$ in RPMI1640 with phytohaemagglutinin, antibiotic (penicillin + streptomycin), L-glutamine and 20\% FCS. After GTG banding, the karyotype was 49,XXXXY in all the cells examined (Fig. 2).

\section{Metabolic and hormonal profile}

High grade of hypergonadotropic hypogonadism: testosterone $<0.025 \mathrm{ng} / \mathrm{ml}$ (normal range 1.42-9.23), luteinising hormone (LH) $18.1 \mathrm{mlU} / \mathrm{ml}$ (normal range 1-9) and follicle-stimulating hormone (FSH) $37.6 \mathrm{mlU} / \mathrm{ml}$ (normal range 1-8). The other hormonal tests were within the normal range: prolactin $6.42 \mathrm{ng} / \mathrm{ml}$ (normal range 1.6-18.8), thyrotrophin (TSH) $1.63 \mu \mathrm{IU} / \mathrm{ml}$ (normal range $0.5-4.5$ ), growth hormone $0.88 \mathrm{ng} / \mathrm{ml}$ (normal range 0.06-5) and adrenocortical hormone $41.1 \mathrm{pg} / \mathrm{ml}$ (normal range $0-46$ ).

A $75 \mathrm{~g}$ oral glucose tolerance test for glycaemia and insulin was performed. The results were: fasting plasma glucose (FPG) $86 \mathrm{mg} / \mathrm{dl}$ and plasma glucose $126 \mathrm{mg} / \mathrm{dl}$ after $2 \mathrm{~h}$, basal insulin $36.8 \mu \mathrm{U} / \mathrm{ml}$ and after $2 \mathrm{~h}$, $159 \mu \mathrm{U} / \mathrm{ml}$ insulin resistance with homeostatic model assessment (HOMA) index 7.8 (normal value <2.5). Furthermore, we observed vitamin $\mathrm{D}$ deficiency: $20.8 \mathrm{ng} / \mathrm{ml}$ (normal range $30-100 \mathrm{ng} / \mathrm{ml}$ ).

\section{Neoplastic markers}

No alterations of lactate dehydrogenase, carcinoembryonic antigen, alpha-fetoprotein and human gonadotrophin.

\section{Ultrasound study}

The study was performed using a $7.5 \mathrm{MHz}$ probe. This investigation showed an evident bilateral testicular hypoplasia: right testicle diameters $12.0 \mathrm{~mm} \times 5.9 \mathrm{~mm} \times$ $6.9 \mathrm{~mm}$; left testicle diameters $11.8 \mathrm{~mm} \times 6.4 \mathrm{~mm} \times$ $6.5 \mathrm{~mm}$; volume (evaluated by ellipsoid formula: length $\times$ width $\times$ height $\times 0.52$ ) was respectively 2.5 and $2.6 \mathrm{ml}$. The echostructure was dishomogeneous (Fig. 3). Right epididymis and left epididymis, although not clinically palpable, were detectable by ultrasound study (US; maximum diameter of the epididymal head was respectively 4.0 and $3.9 \mathrm{~mm}$ ).

\section{Treatment}

The patient was treated with hormonal replacement therapy. Oral testosterone undecanoate $40 \mathrm{mg}$ /day was administered for 3 months; then the dose was increased to $120 \mathrm{mg} /$ day, with a significant increase in plasma testosterone levels (Table 1).

The patient was also treated with cholecalciferol supplementation for 3 months with consequent normalisation of blood values.

\section{Outcome and follow-up}

The clinical and laboratory data showed normalisation of testosterone levels, an increase in pubic hair growth, testicular volume (right $7.9 \mathrm{ml}$ and left $7.8 \mathrm{ml}$ ) and size of the penis (from 2.1 to $8.2 \mathrm{~cm}$ stretched) (Fig. 1a and b); weight loss (BMI from 36.2 to $33.1 \mathrm{~kg} / \mathrm{m}^{2}$ ); a reduction in

Table 1 Testosterone and gonadotrophins values baseline and after 3, 6, 9 and 12 months of therapy with testosterone undecanoate.

\begin{tabular}{|c|c|c|c|c|c|c|}
\hline & Normal values & Basal & 3 months (40 mg) & 6 months $(80 \mathrm{mg})$ & 9 months $(120 \mathrm{mg})$ & 12 months $(120 \mathrm{mg})$ \\
\hline $\begin{array}{l}\text { Testosterone } \\
(\mathrm{ng} / \mathrm{ml})\end{array}$ & $1.42-9.23$ & $<0.025$ & 0.207 & 0.407 & 0.770 & 1.59 \\
\hline $\mathrm{FSH}(\mathrm{mlU} / \mathrm{ml})$ & $1-8$ & 37.6 & 35.43 & 28.24 & 36.13 & 26.5 \\
\hline LH (mlU/ml) & $1-9$ & 18.1 & 19.76 & 21.66 & 27.13 & 20.96 \\
\hline
\end{tabular}


the HOMA index (from 7.8 to 3.2); and normalisation of vitamin D values (from 20.8 to $52 \mathrm{ng} / \mathrm{ml}$ ), even after the interruption of replacement therapy.

Finally, we also observed the patient's improved interaction with the social environment and context, improved posture, gait and postural autonomy in walking.

\section{Discussion}

This rare aneuploidy, 49, XXXXY syndrome, is caused by three extra $\mathrm{X}$ chromosomes in subjects phenotypically male. It is characterised by complex plurimalformative syndrome: musculoskeletal anomalies (3); alteration of neurocognitive development and brain malformations, such as white matter lesions (5); metabolic and hormonal alterations, such as hypergonadotropic hypogonadism, hypothyroidism and diabetes mellitus (6) (7) (8); and increased susceptibility to infection, atopy and immunodeficiency (9). For this reason, the treatment of these subjects requires a multidisciplinary team (endocrinology, psychoneurology, orthopedics, physical medicine, speechlanguage therapy).

In our case, testosterone replacement therapy, even though delayed, had positive effect on the development of the reproductive system and many other functions: the patient was able to better interact with the social context; there was an improvement in the metabolic profile with weight loss, a reduction of the HOMA index and a normalisation of vitamin $\mathrm{D}$ values.

This is due to the fact that testosterone, beyond regulating the sexual and reproductive functions, seems to play a key role in neurocognitive development (6) and in maintaining male characteristics and behaviours (10). Moreover, in patients affected by hypogonadism, testosterone replacement has a positive effect on glycometabolic control (insulin resistance, type 2 diabetes and metabolic syndrome), visceral obesity, cardiovascular function and bone health (10).

In conclusion, in patients with plurimalformative syndrome, cognitive impairment and, primarily, delayed puberty, it is necessary to confirm any presence of hypogonadism and metabolic disorders due to genetic causes as soon as possible. Early and timely hormonal replacement in such patients could, in fact, improve the quality of life for them and their families.
Declaration of interest

The authors declare that there is no conflict of interest that could be perceived as prejudicing the impartiality of the research reported.

\section{Funding}

This research did not receive any specific grant from any funding agency in the public, commercial or not-for-profit sector.

\section{Patient consent}

Written informed consent has been obtained from the patient's guardian for publication of the case report and accompanying images.

\section{Author contribution statement}

$\mathrm{R}$ Mazzilli was the principal clinical investigator who interpreted the data and wrote the paper. M Delfino performed ultrasound investigation and critical revision of the article. J Elia and F Benedetti assembled hormonal and biochemical data. L Alesi performed genetic investigations. $L$ Chessa was the genetic coordinator who performed critical revision of the article. F Mazzilli was the clinical coordinator and supervisor who performed critical revision of the article.

\section{References}

1 Fraccaro M, Kaijser K \& Lindsten J 1960 A child with 49 chromosomes. Lancet 2 899-902. (doi:10.1016/S0140-6736(60)91963-2)

2 Tartaglia N, Ayari N, Howell S, D'Epagnier C \& Zeitler P 2011 48,XXYY, 48,XXXY and 49,XXXXY syndromes: not just variants of Klinefelter syndrome. Acta Paediatrica 100 851-860. (doi:10.1111/j.1651-2227.2011.02235.x)

3 Sprouse C, Tosi L, Stapleton E, Gropman AL, Mitchell FL, Peret R, Sadeghin T, Haskell K \& Smango-Sprouse CA 2013 Musculoskeletal anomalies in a large cohort of boys with 49,XXXXY. American Journal of Medical Genetics. Part C, Seminars in Medical Genetics 163 44-49. (doi:10.1002/ajmg.c.31354)

4 Peitsidis P, Manolakos E, Peitsidou A, Petersen MB, Tsoplou P, Kadir R \& Agapitos E 2009 Pentasomy 49,XXXXY diagnosed in utero: case report and systematic review of antenatal findings. Fetal Diagnosis and Therapy 26 1-5. (doi:10.1159/000236351)

5 Gropman A \& Samango-Sprouse CA 2013 Neurocognitive variance and neurological underpinnings of the $\mathrm{X}$ and $\mathrm{Y}$ chromosomal variations. American Journal of Medical Genetics. Part C, Seminars in Medical Genetics 163 35-43. (doi:10.1002/ajmg.c.31352)

6 Samango-Sprouse CA, Gropman AL, Sadeghin T, Kingery M, Lutz-Armstrong M \& Rogol AD 2011 Effects of short-course androgen therapy on the neurodevelopmental profile of infants and children with 49,XXXXY syndrome. Acta Paediatrica 100 861-865. (doi:10.1111/j.1651-2227.2011.02252.x)

7 Wikiera B, Głab E, Slezak R, Wójcik E \& Noczyńska A 2009 Sex chromosome pentasomy 49,XXXXY connected with hypothyroidism. Case report. Pediatric Endocrinology, Diabetes, and Metabolism 15 125-127.

8 Kim HJ, Kim D, Shin JM, Chung HK \& Lee G 2006 49,XXXXY syndrome with diabetes mellitus. Hormone Research 65 14-17. (doi:10.1159/000090327)

9 Keller MD, Sadeghin T, Samango-Sprouse C \& Orange JS 2013 Immunodeficiency in patients with 49,XXXXY chromosomal variation. American Journal of Medical Genetics. Part C, Seminars in Medical Genetics 163 50-54. (doi:10.1002/ajmg.c.31348)

10 Corona G, Vignozzi L, Sforza A \& Maggi M 2013 Risks and benefits of late onset hypogonadism treatment: an expert opinion. World Journal of Men's Health 31 103-125. (doi:10.5534/wjmh.2013.31.2.103) 